\title{
O ensino libertário e a relação entre trabalho e educação: algumas reflexões*
}

\author{
Carmen Sylvia Vidigal Moraes \\ Tatiana Calsavara \\ Ana Paula Martins \\ Universidade de São Paulo
}

Contato:

Carmen Sylvia Vidigal Moraes

Universidade de São Paulo

Faculdade de Educação

Departamento de Administração

Escolar e Economia da Educação

São Paulo/SP

moraescs@usp.br

* Projeto de pesquisa financiado pelo CNPq. 0 texto, apresentado na $33^{\text {a }}$ Reunião Anual da Associação de PósGraduação em Educação (ANPEd), 2010, constitui versão resumida de estudo que integra o livro Educação Libertária no Brasil. Inventário de Fontes: Acervo João Penteado (São Paulo: Edusp; Fapesp, no prelo).

\section{Resumo}

Um dos principais desafios nos estudos a respeito da pedagogia escolar anarquista consiste, precisamente, em apreender os conteúdos de ensino. Com essa preocupação, este texto tem triplo objetivo: analisar a proposta educativa da instituição a cargo do professor libertário João Penteado, em São Paulo, nas primeiras décadas do século XX; indicar aspectos considerados relevantes relacionados à concepção de educação integral e à forma como o trabalho está presente na organização do ensino; e, por fim, apresentar alguns apontamentos de pesquisa que possam contribuir para sua continuidade e seu aprofundamento. Optouse por abarcar período relativo a dois momentos de existência da escola dirigida por João Penteado - a Escola Moderna № 1 (19121919) e a Escola Nova (1920-1923). Entende-se que a cronologia definida consegue abranger a pluralidade de práticas escolares necessárias aos propósitos da análise. A documentação utilizada limita-se basicamente a jornais e demais fontes produzidas e/ou acumuladas nos diferentes períodos de existência da(s) escola(s), em particular, os jornais Boletim da Escola Moderna, Boletim da Escola Nova, Boletim da Academia Saldanha Marinho, O Início, $O$ Iris. No estudo do primeiro período, que coincide com o da Escola Moderna, são também utilizadas notícias publicadas por alguns jornais da imprensa operária e anarquista, como $A$ Lanterna, A Vida e O Amigo do Povo, entre outros.

\section{Palavras-chave}

Movimento anarquista - Ensino libertário - Educação integral. 


\section{Libertarian teaching and the relationship between labor and education: some reflections*}

Carmen Sylvia Vidigal Moraes

Tatiana Calsavara

Ana Paula Martins

Universidade de São Paulo

\section{Contact: \\ Carmen Sylvia Vidigal Moraes Universidade de São Paulo Faculdade de Educação Departamento de Administração Escolar e Economia da Educação São Paulo/SP \\ moraescs@usp.br}

* Research Project funded by CNPq (National Research Council). The text, presented at the 33rd Annual Meeting of National Association of Graduate Research on Education (ANPEd), in 2010, is a summarized version of a study that is a chapter of the book Libertarian education in Brazil. Inventory of Sources: João Penteado Collection (São Paulo: Edusp; Fapesp, in the press).

\begin{abstract}
One of the major challenges in the studies on anarchist school pedagogy consists precisely of apprehending the contents of teaching. Assuming that concern, this text has three-fold objective: to analyze the educational proposal of the institution that libertarian teacher João Penteado was in charge of, in the city of São Paulo, in the first decades of the 20th century; to indicate significant aspects of the concept of integral education and the way labor is present in the organization of teaching; and, finally, to present some research notes that may contribute to a further and in-depth study. A choice was made to encompass the period when two moments in the life of the school run by João Penteado - the Modern School $N^{o} 1$ (1912-1919) and the New School (1920-1923). It is understood that the chronology so defined is able to include the plurality of the school practices required for the purpose of analysis. The documentation utilized is basically limited to newspapers and other sources produced and/or accumulated in the different periods during which the school(s) existed, especially, the newspapers Boletim da Escola Moderna (the Modern School newsletter), Boletim da Escola Nova (the New School newsletter), Boletim da Academia Saldanha Marinho (the Saldanha Marinho Academy newsletter), 0 Início (the Beginning), 0 Iris (the Iris). In the study of the first period, simultaneous with the Modern School, there are also news published bsão by some newspapers of the working-class and anarchist press, including A Lanterna (the Lantern), A Vida (the Life) and 0 Amigo do Povo (the Friend of the People).
\end{abstract}

\section{Keywords}

Anarchist movement - Libertarian teaching - Integral education. 


\section{As concepções anarquistas de educação}

Entre o final do século XIX e o início do século XX, surgiram na Europa e em vários países do continente americano movimentos de renovação pedagógica de cunho libertário ${ }^{1}$. Esses movimentos criticavam a falta de acesso dos trabalhadores à educação e também os métodos tradicionais de ensino, propondo que a educação fosse integral, racional e científica. A literatura tem assinalado a importância estratégica da educação no âmbito do movimento anarquista, por meio de obras escritas por seus militantes mais representativos nos diferentes momentos da luta libertária Proudhon (1809-1865), Bakunin (1814-1876), Reclus (1830-1905), Kropotkin (1842-1921) e Malatesta (1853-1932) - e de experiências pedagógicas concretas que se tornaram referências internacionais - fundação e manutenção de escolas, centros de estudos e universidades populares. Dentre tais instituições, destacam-se a Escola de Iasnaia Poliana, a Escola Moderna de Barcelona, a La Ruche, o Orfanato de Prévost e a Escola Oficina $\mathrm{N}^{\circ} 1^{2}$.

Este texto não se propõe a detalhar essas contribuições, mas a demarcar, nas práticas de ensino das escolas em estudo, aspectos centrais da crítica anarquista à educação escolar burguesa, bem como alguns dos pressupostos orientadores de sua proposta educativa. Tais concepções pedagógicas constam, em primeiro lugar, do Programa de Ensino Integral, elaborado por Paul Robin e apresentado nos Congressos da Internacional de Trabalhadores em Lausane (1867) e em Bruxelas (1868), sendo, finalmente, incorporado ao Programa Educacional do

1 - Sobre o movimento libertário e o pensamento educacional, consultar Tomassi (1988), Codello (2007), Moriyón (1989) e Solà (1978).

2- A Escola de lasnaia Poliana foi fundada por Leon Tolstói, na Rússia; a Escola Moderna de Barcelona ficou mundialmente conhecida pela forma trágica como morreu seu fundador, Francisco Ferrer; o Orfanato Prévost teve como professor Paul Robin, que influenciou diretamente Sebastien Faure a criar La Ruche (A Colmeia), ambas na França; a Escola Oficina № 1 , em Lisboa, possuiu em seu quadro docente o professor anarquista Adolfo Lima, defensor da educação integral.
Comitê para o Ensino Anarquista, de 1882, após o encerramento da Internacional (1876) ${ }^{3}$.

Apesar dos conflitos entre as diferentes correntes políticas, a concepção de educação integral e igualitária foi assumida consensualmente como exigência prioritária pela Primeira Internacional, por Bakunin e Marx, e pelas tendências que ambos representavam. Segundo eles, o desenvolvimento da consciência revolucionária faz-se também pela educação popular, pela instrução da população. Por isso, a Comuna de Paris, mesmo durante os períodos de luta mais sangrenta, "não deixou de fundar escolas laicas e humanitárias para a infância parisiense" e as organizações operárias de tendência anarquista

não descuidaram nem em seus momentos mais difíceis da criação de escolas elementares para a educação dos trabalhadores e de seus filhos. (CAPELLETTI, 2000, p. 28)

Pensadores da pedagogia antiautoritária do século XIX, como Paul Robin, e do século XX, como Francisco Ferrer e Adolfo Lima $^{4}$, aparecem com frequência no noticiário da imprensa operária brasileira. Conceitos marcantes no período, como os de educação integral, resgatado do programa de Robin, e ensino racionalista, inspirado nos trabalhos de Ferrer, são analisados e discutidos. A questão da relação entre trabalho e educação, presente na proposta de Robin, ganhou algum destaque em publicações do movimento operário. 0 trabalho é visto como o principal princípio educativo e a produção social, como a própria vida do homem. Assim, uma educação ligada à vida deveria, necessariamente, levar em conta a atividade produtiva do homem (CALSAVARA, 2004). Nessa direção, torna-se importante considerar, em primeiro lugar,

3 - A esse respeito, ver também Luizetto (1986, 1987) e Moraes et al. (2011). 4 - Adolfo Lima, pedagogo anarquista pouco estudado pelos pesquisadores da pedagogia libertária, nasceu em Portugal (1874-1943) e, a partir de 1911 dedicou-se ao ensino integral e ao anarquismo. Dirigiu a Escola Oficina № 1 , em Lisboa, e suas obras foram recomendadas aos operários na imprensa operária. A esse respeito, ver Calsavara (2004, p. 103). 
que o desenvolvimento do anarquismo se dá no bojo das discussões sobre as condições de trabalho a que estavam submetidos os operários no século XIX. A intrínseca relação entre anarquismo e trabalho marca as propostas de educação elaboradas pelos movimentos anarquistas. A educação é vista como instrumento de transformação social e, se tem como pressuposto a liberdade, seu fim efetivo consiste na realização da igualdade. Para tanto, é necessário romper a divisão entre trabalho manual e trabalho intelectual, que se expressa também na dualidade escolar, nas diferenças entre o que é ensinado às classes dominantes e ao proletariado, e contribui para a reprodução das desigualdades sociais. 0 conceito de educação integral desenvolve-se no âmbito dessas preocupações. Segundo Francesco Codello (2007),

a educação integral se transforma [...] em um meio revolucionário e eficaz para construir uma sociedade libertária. Uma vez que o projeto político de Bakunin prevê a abolição completa e definitiva das classes, é claro que somente por meio dessa integração do trabalho manual e intelectual torna-se possivel atingir tal objetivo. Para isso, é necessário impedir que a ciência e as artes fundamentem seus benefícios apenas em uma pequena parte da humanidade, mas que se tornem patrimônio de todos. E se esses progressos, que tais saberes realizaram e realizam, permanecerem poder de poucos, tornam-se fontes de escravidão intelectual e, portanto, também material para o povo, porque aumentam sempre mais o abismo que já separa a inteligência popular daquela das classes privilegiadas. (p. 117)

0 ensino racionalista do educador espanhol Francisco Ferrer $^{5}$ figura como a principal influência entre os libertários brasileiros. Sua morte por fuzilamento, em 1909, impulsionou a divulgação de seu método de

5 - Sobre Ferrer e a Escola Moderna de Barcelona, ver Tragtenberg (1978). ensino. A proposta de Ferrer não destaca tanto quanto as anteriores a relação entre ensino e trabalho, mas enfatiza, igualmente, a necessidade de os trabalhadores terem acesso aos conhecimentos científicos para que sua inteligência fosse "capaz de se emancipar e formar racionalmente convicções próprias” (FERRER Y GUARDIA, 1970, p. 33).

Em $A$ boa educação, ao apresentar uma compilação das experiências e teorias libertárias na Europa, Francesco Codello (2007) considera que

essa história de educação libertária é uma mescla contínua de teorias e experiências, de ideias anarquistas aplicadas à educação, mas também de teorias e práticas organizativas e didáticas que frequentemente [...] podem remeter ao anarquismo. Do fim de uma experiência nasce uma iniciativa de difusão e de agregação (como no caso da Liga pela Educação Libertária criada por Émile Janvion e Jean Degalvès, em 1897, depois do final da obra de Paul Robin, em Cempuis). (p. 20)

Apesar de suas diferenças, as pedagogias anarquistas convergem ao defender a integração entre trabalho intelectual e trabalho manual, o valor da experimentação pessoal e direta, o jogo como atividade pedagógica coletiva privilegiada; tendem a suprimir os exames e demais procedimentos associados à concepção tradicional de avaliação, como os prêmios e os castigos, as competências acadêmicas etc., ao mesmo tempo em que estimulam "a solidariedade, a curiosidade desinteressada, a ânsia de saber, a liberdade para pensar, escrever e construir etc." (CAPELLETTI, 2000, p. 28).

Esses modelos teóricos, alinhados às realizações concretas dos fins do século XIX e inícios do século XX, estavam também presentes nas experiências de educação libertária no Brasil e, por meio da vida e da obra do professor João Penteado, podemos identificar algumas de suas formas de resistência, mesmo após o episódio de fechamento da escola em 1919. 


\section{Ensino e trabalho nas escolas dirigidas por João Penteado}

Uma das questões mais importantes a serem enfrentadas nos estudos e nas pesquisas sobre a pedagogia escolar anarquista consiste na apreensão dos conteúdos de ensino. No que se refere à Escola Moderna № 1 e às instituições posteriores aos cuidados do professor libertário João Penteado ${ }^{6}$, pretende-se apontar alguns aspectos considerados relevantes relacionados à concepção de educação integral e à forma como o trabalho está presente em sua organização. A documentação utilizada limita-se basicamente aos jornais e demais fontes produzidas ou acumuladas nos diferentes períodos de existência da(s) escola(s), em particular: os jornais Boletim da Escola Moderna, Boletim da Escola Nova, Boletim da Academia Saldanha Marinho, $O$ Início e $O$ Iris. No estudo do primeiro período, que coincide com o da Escola Moderna, são também utilizadas notícias publicadas por alguns jornais da imprensa operária e anarquis$\mathrm{ta}^{7}$. Os livros sobre educação integral e racional adquiridos pelo professor João Penteado constituem fontes relevantes. Vale ressaltar que há significativa literatura educacional no acervo do educador, indicando sua permanente preocupação com a formação teórica.

\section{Escola Moderna}

Assim como na Europa, as ideias anarquistas difundem-se, no Brasil, no âmbito do movimento operário, trazidas principalmente por imigrantes europeus. Entendendo que a falta de acesso ao conhecimento contribuía para manter a situação de opressão à qual os trabalhadores estavam submetidos, os anarquistas

6- Sobre o educador João Penteado, suas concepções e a atuação militante, consultar Moraes et al. (2011), Santos (2009) e Calsavara (2004). 7- As fontes escolares analisadas pertencem ao Acervo João Penteado, do Centro de Memória da Educação da Faculdade de Educação (USP). Doado por parentes do educador, o acervo possui cerca de 37.610 documentos administrativos e pedagógicos, 4.800 fotos, 300 exemplares de jornais elaborados por professores e alunos, 167 peças museológicas. 0 arquivo pessoal, organizado separadamente, reúne 751 documentos (fotos, livros, peças de teatro, poemas, textos didáticos e correspondências) (MORAES et al., 2011). dirigiram diversos esforços à abertura de centros de leitura, centros de cultura e escolas.

As experiências das escolas libertárias, as de São Paulo e as organizadas por todo o país, sugerem que o movimento libertário alcançou mais densidade do que geralmente faz supor a história do anarquismo brasileiro, centrado nas greves e reivindicações trabalhistas. As iniciativas e os esforços empreendidos para promover a educação, sobretudo em sua forma escolar, indicam que segmentos expressivos de trabalhadores, ainda que de modo incipiente, organizaram-se vislumbrando alcançar mudanças profundas na sociedade. As iniciativas de cunho educacional agregaram tanto militantes imigrantes - como Orestes Ristori, Gigi Damiani, Adelino de Pinho, Florentino de Carvalho, e Neno Vasco - quanto militantes brasileiros como Edgard Leuenroth, Octavio Brandão, João Penteado, José Oiticica, Rodolpho Felipe e Zeferino Oliva, entre outros ${ }^{8}$. Destes, João Penteado, Adelino de Pinho e Florentino de Carvalho estiveram diretamente relacionados ao funcionamento de escolas libertárias, sobretudo em São Paulo (LUIZETTO, 1986; SANTOS, 2009). 0 fuzilamento de Francisco Ferrer na Espanha, em 1909, provocou intensa reação e mobilização, e no calor dos embates formou-se a Comissão Pró-Escola Moderna, que, entre 1909 e 1912, procurou criar as condições necessárias ao desenvolvimento do ensino libertário em São Paulo.

Os documentos indicam que o movimento libertário assimilou os pressupostos da educação integral, sistematizados por Paul Robin no Orfanato de Cempius (França), e do ensino racional, organizado e difundido por Ferrer na Escola Moderna de Barcelona. Tais concepções, complementares, consistem nos dois grandes enfoques da Escola Moderna em São Paulo, os quais propunham romper com a educação oficial representada pelo Estado e pela Igreja Católica. Os libertários opunham-se

8 - Orestes Ristori era italiano, assim como Luigi Damiani, mais conhecido no Brasil como Gigi Damiani; Adelino de Pinho e Neno Vasco eram portugueses, e Florentino de Carvalho, espanhol. 
abertamente à aprendizagem parcial, voltada para o trabalho, com o objetivo único de formar mão de obra para a indústria. 0 movimento defendia o desenvolvimento completo do homem e, por isso, a ênfase também na educação informal, para cuja realização criou inúmeras e variadas estratégias de intervenção pedagógica nos diferentes espaços sociais. Com a mesma proposta de levar o trabalhador à formação integral e à consciência de classe, organizaram-se várias bibliotecas populares, centros de estudos e de cultura social, grupos de teatro e variados jornais - mensais, semanários, diários, revistas - que obtiveram ressonância entre os trabalhadores e no conjunto da sociedade da época. Essa imprensa foi grande difusora de propagandas e informações de caráter educativo, visando ao público trabalhador 9 .

O Boletim da Escola Moderna, ao recordar a morte de Francisco Ferrer, homenageia o educador transcrevendo seu artigo sobre o racionalismo humanitário, no qual a perspectiva classista do trabalho e da educação é apresentada com clareza:

Se a classe trabalhadora se libertasse do preconceito religioso e conservasse o da propriedade, tal qual hoje existe, se os operários julgassem como certa a parábola de que sempre deve haver pobres e ricos; se o ensino racionalista se contentasse com difundir conhecimentos sobre higiene, sobre as ciências naturais e preparasse somente bons aprendizes e bons dependentes, bons empregados e bons trabalhadores de todos os ofícios, poderíamos viver entre ateus, mais ou menos sãos e robustos segundo o escasso alimento que podem permitir os minguados salários, mas não deixaríamos de nos encontrar sempre entre escravos do capital. A Escola Moderna pretende combater quantos preconceitos dificultem

9- Dentre os jornais da imprensa operária e da imprensa anarquista encontram-se: A Plebe (São Paulo), A Hora Social (Recife), Voz do Povo (Rio de Janeiro), Vanguarda (São Paulo), A Lanterna (São Paulo), O Amigo do Povo (São Paulo), A Terra Livre (São Paulo/Rio de Janeiro), La Bataglia (São Paulo). a emancipação total do indivíduo e para isso adota o racionalismo humanitário que consiste em inculcar na infância o afã de conhecer a origem de todas as injustiças sociais para que com o seu conhecimento possa logo combate-las e opor-se a eles. 0 novo racionalismo humanitário combate as guerras fratricidas, sejam intestinas ou exteriores, combate a exploração do homem pelo homem, combate a relegação da mulher e combate a todos os inimigos da harmonia humana, como são a ignorância, a maldade, a soberba e outros vícios e defeitos que têm dividido os homens em tiranos e tiranizados. ${ }^{10}$

A concepção e a importância do trabalho no processo de ensino das escolas dirigidas por João Penteado manifestam-se nos aspectos organizacionais e administrativos das instituições e em suas variadas dimensões e atividades pedagógicas - público alvo, corpo docente, cursos ofertados, conteúdos e métodos de ensino. No que se refere à origem da escola e à composição social dos promotores da iniciativa, embora os anarquistas exercessem hegemonia, a comissão reunia grupo heterogêneo do ponto de vista político - liberais, anticlericais, republicanos, socialistas, maçons -, isto é, livres pensadores que convergiam na defesa de alguns princípios, como a secularização da sociedade, a laicidade do ensino, a educação científica, democrática e igualitária. A diversidade ideológica é acompanhada pela heterogeneidade social. Vários participantes do Comitê Pró-Escola Moderna eram dirigentes anarquistas, militantes do movimento operário e/ou jornalistas ligados à imprensa operária. Havia, entretanto, segundo informa A Terra Livre (1 jan. 1910), pessoas de outras orientações profissionais, como Leão Aymoré, guarda-livros, Dante Ramenzoni e Pedro Lopes, industriais, José Sanz Duro, negociante, e Tobias Bore, artífice (CALSAVARA, 2004; SANTOS, 2009). A participação de trabalhadores e de suas

10-Boletim da Escola Moderna, n. 3, 13 out. 1919. 
entidades organizativas é notificada por João Penteado em anúncios do Boletim da Escola Moderna sobre a doação de recursos para a manutenção da instituição: Sindicato dos Laminadores (30\$000), União dos Chapeleiros de São Paulo (50\$000), Liga dos Padeiros e Confeiteiros (5000), Sindicato Proletário de Sabaúna (10\$000), Sindicato dos Canteiros de Lageado (20\$000), União dos Artífices em Calçados $(22 \$ 000)^{11}$.

A respeito da relação das escolas racionalistas com o movimento operário e sindical, Antonio José Marques (1992) observa que

o relacionamento sempre foi umbilical: quando este era ascendente, as escolas também o eram, quando o movimento entrava em declínio, as escolas também o sentiam. (p. 4)

De fato, a criação do Comitê Pró-Escola Moderna $^{12}$ dá-se em período de declínio do movimento operário, atingido pela onda de repressão iniciada pelo governo paulista após a greve geral de 1907, momento em que é desarticulada a Confederação Operária Brasileira (COB) e extinto seu órgão oficial, o jornal $A V o z d o$ Trabalhador, cujo último número circulou em dezembro de 1909 (sendo o jornal reativado em 1913). A inauguração da Escola Moderna No 1 ocorre em 1912, justamente quando o movimento operário e sindical começa a reorganizar-se. Seu fechamento em 1919, em meio a uma nova investida repressiva, culmina no estado de sítio decretado por Artur Bernardes e no fechamento das associações operárias, na prisão

11 - Boletim da Escola Moderna, n. 1, 1918; n. 2, 1919.

12- Segundo A Lanterna (n. 22, 12 mar. 1910), a intenção inicial era fazer da Escola Moderna de São Paulo o centro irradiador do movimento anarquista no Brasil, a exemplo da Escola Moderna de Barcelona, o que consistia em grande desafio para um movimento em formação. Além da falta de recursos, não havia professores capacitados, como indica o convite feito pelos pais dos alunos da escola dos vidreiros a Edmundo Rossini, para que viesse da Itália assumir 0 ensino na instituição. Esse professor ficou pouco tempo no Brasil, tendo sido expulso pelo governo, no final de 1909, por sua participação na greve dos operários da Fábrica Santa Marina. A esse respeito, ver Marques (1992) e Jomini (1990). e deportação de seus militantes para o campo de concentração do Oiapoque, na Clevelândia.

A ligação entre a escola e o universo do trabalho manifesta-se, de imediato, na localização do estabelecimento no bairro operário do Belenzinho, em seu objetivo de alcançar o público trabalhador. Tal como a Escola Moderna de Barcelona, em São Paulo a escola era privada. 0 Comitê Organizador cobrava mensalidades de seus alunos, as quais, nas aulas diurnas, variavam entre $3 \$ 000$ e $4 \$ 000$, segundo o adiantamento. Nas aulas noturnas, destinadas a adultos, a mensalidade era a combinar, provavelmente uma maneira de o valor estipulado levar em conta a situação econômica do aluno trabalhador. Os valores cobrados eram basicamente os mesmos para as aulas preliminares diurnas da Escola Moderna $N^{\circ} 2$ e da Escola Nova, dirigidas respectivamente por Adelino de Pinho e Florentino de Carvalho, ambas situadas nos bairros operários do Braz e da Mooca ${ }^{13}$. Apesar das taxas pagas pelos alunos, a Escola Moderna não dispensava as listas de subscrição, nas quais os trabalhadores e simpatizantes ofertavam suas contribuições. Tais listas foram publicadas nos jornais O Início (1914, 1915, 1916), elaborado por alunos da escola, e Boletim da Escola Moderna (1918, 1919), dirigido pelo próprio João Penteado. Além disso, realizavam-se, com frequência e com o apoio da imprensa operária e anarquista, festividades, recitais de poesia e bailes abertos ao público, cuja renda era destinada à manutenção da escola. Os balancetes de entradas, saídas e gastos de recursos são também publicados nos jornais, garantindo a transparência financeira da instituição. Embora fosse grande o esforço para manter a escola, não foi possível evitar certas dificuldades, como a interrupção do jornal elaborado pelos alunos, provocada pela falta de recursos para viabilizá-lo. No que se refere aos cursos ofertados na Escola Moderna, no anúncio publicado em $A$ Plebe (1917), lê-se que a instituição pretendia proporcionar:

13 - Boletim da Escola Moderna, 18 mar. 1919. 
Ensino teórico e prático, segundo os métodos da pedagogia moderna, com os quais se ministra aos alunos uma instrução que os habilita para o início das atividades intelectuais e profissionais, assim como uma educação moral baseada no racionalismo científico.

Constam do programa as seguintes disciplinas: português, aritmética, geografia, história, desenho, caligrafıa, préstimos. As aulas de desenho estavam a cargo de Isabel Ramal, presidenta da Associação Artística do Braz, e as outras aulas distribuídas entre João Penteado e sua irmã, d. Sebastiana Penteado ${ }^{14}$. Importante notícia, publicada por $O$ Início, informa que, nesses anos, "achavam-se funcionando aulas do curso de preparatório para artífices e para as de música" ${ }^{15}$, tendo por professores, respectivamente, os senhores Leopoldo Guedes e Alfredo Avellar. Essa foi a única menção à oferta de aulas para artífices, e, nos anos posteriores (1918 e 1919), de acordo com o Boletim da Escola Moderna, passam a ser realizadas, no período noturno, "aulas especiais" do "curso de datilografıa, português e aritmética” ${ }^{16}$. A realização de aulas preparatórias para artífices ao lado das aulas de música anuncia a perspectiva integradora do ensino. Essa perspectiva é confirmada por outra notícia do Boletim de 1918. Segundo ele, a escola passaria a realizar aulas de inglês e francês, no período noturno, três vezes por semana. Os cursos seriam desenvolvidos pelo "inteligente camarada Cleto Trombetta", que se "oferecera" para o trabalho. 0 professor, embora italiano, tinha "boa pronúncia" pois residira “durante anos em França e Inglaterra”. Não se esclarece se o professor realizaria serviço voluntário e se as aulas seriam gratuitas. Mas, de qualquer maneira, a oferta das aulas de línguas estrangeiras no período da noite indica ser o trabalhador adulto o seu destinatário.

\footnotetext{
14 - Boletim da Escola Moderna, n. 1, 13 out. 1918

15 - O Início, n. 3, 19 ago. 1916.

16 - Boletim da Escola Moderna, n. 1, 13 out. 1918.
}

Além das aulas, realizavam-se, nos finais de semana, sessões escolares com o objetivo de reunir a família dos alunos, trabalhadores e interessados na pedagogia racionalista. Nessas conferências - prática comum no movimento -, é evidente o objetivo pedagógico de contribuir para a formação crítica dos trabalhadores e de suas famílias, e o ângulo de visão assumido "é sempre o da classe operária" (LIMA; VARGAS, 1986, p. 177), num plano que transcende a particularidade das culturas nacionais ou étnicas, isto é, na perspectiva internacionalista. Os temas são tão variados quanto os previstos pelas teorias libertárias. Há conferências sobre a questão operária, economia, a situação da mulher, as condições de trabalho ou comportamentos.

Os jornais escolares, em particular os quatro números de $O$ Início, narram outras práticas educativas vivenciadas pelos alunos, além das aulas diárias. De caráter eminentemente pedagógico, a publicação apresenta, em suas diferentes seções - Notas da Redação, Exercícios de Descrição, Exercícios Epistolares, Exercícios Vários e Anúncios -, material valioso sobre o cotidiano escolar, o qual, de certa maneira, pode amenizar a lacuna provocada pela ausência de outras fontes documentais. 0 formato do jornal e sua organização expressam uma concepção de método de ensino que valoriza aulas ao ar livre e excursões educativas, de modo a promover o contato com situações variadas da vida na cidade e com a natureza. 0 recurso aos estudos do meio permitia integrar as diferentes dimensões do conhecimento na análise da realidade. Na perspectiva da relação ensino e aprendizagem, a sala de aula tradicional "favorecia a passividade"; por isso, o professor deveria estimular os alunos a participarem de atividades diferenciadas, interagindo com pessoas, lugares, observando atividades profissionais na indústria, no comércio e no campo. Somente uma educação para a liberdade formaria um indivíduo autônomo, "capaz de fazer suas próprias escolhas” (GRAVE, 1991, p. 3-4).

Nos exercícios descritivos ou nos epistolares, aparecem conteúdos e temáticas que 
remetem direta ou indiretamente à relação entre escola e vida social, ao significado do trabalho na conformação do ensino:

Nos sábados nos reunimos as 7 horas da manhã na nossa escola cantamos os hinos "A mulher" e o "Primeiro de Maio". ${ }^{17}$

[...] vejo sobre um caixão o jornal chamado A Voz do Trabalhador, um relógio, um copo, uma tampa de moringue. ${ }^{18}$

Textos, anúncios, propagandas e comemorações de datas festivas publicados pelo Boletim da Escola Moderna traduzem a mesma preocupação. Artigos sobre Francisco Ferrer, a Comuna de Paris, a Revolução Russa, o Primeiro de Maio, a Escola Racionalista e seus objetivos, escritos por João Penteado ou outros autores, em geral militantes do movimento anarquista, são difundidos pelo órgão escolar:

Porque vence o porvir? É este o título de um interessante folheto, contendo uma bela conferência pronunciada pela nossa distinta colega d. Maria Lacerda Moura, de Barbacena (Minas), na sede da Liga dos Homens do Trabalho, que merece a visita de todos que se dedicam à propaganda da organização operária. ${ }^{19}$

\section{Escola Nova}

A Escola Moderna $N^{0} 1$ é fechada em 1919 pelo governo paulista sob a alegação de que esta se constituía em instituto voltado

para a corrupção do operário, nos moldes da Escola Moderna de Barcelona, o ninho do anarquismo de onde saíram os piores bandidos prontos a impor suas idéias. (RODRIGUES, 1992, p. 69)

\footnotetext{
17 - Edmundo Mazzone, O Início, n. 2, 4 dez. 1915.

18 - Jácomo Romolo, O Início, n. 2, 4 dez. 1915

19 - Boletim da Escola Moderna, n. 1, 13 out. 1918.
}

Após o fechamento da Escola Moderna pela Diretoria da Instrução Pública, João Penteado vai dirigir outra instituição, a Escola Nova. Não se sabe se essa é a Escola Nova anunciada nas páginas de $O$ Início nos anos 1917 e 1918, ou outra criada pelo educador com a mesma denominação. 0 interessante é que, no jornal da escola, ela aparece como "Estabelecimento de Instrução e Educação Fundado em 1912"20, mesmo ano de criação da Escola Moderna. Outro detalhe que pode reforçar a perspectiva de continuidade entre as duas escolas consiste na permanência do nome do jornal dos alunos, prática retomada na Escola Nova: O Início. Uma nova numeração é iniciada, mas o nome é o mesmo ${ }^{21}$. Para poder funcionar, obteve, tal como a Escola Moderna, o reconhecimento oficial (regulamentada pelo Decreto Federal de 5 de janeiro de 1905 e autorizada pela Diretoria da Instrução Pública, de acordo com a Lei Estadual $\mathrm{n}^{\circ}$ 1579, de 14 de dezembro de 1917). Sua localização continua a ser o bairro operário do Belenzinho, na Rua Saldanha Marinho, $\mathrm{n}^{\circ}$ 8. Surge como estabelecimento particular, em regime de internato e externato, e é mantida com as mensalidades pagas pelos alunos. Não há, agora, listas de subscrição e auxílios de pessoas ou de associações operárias, pelo menos de modo explícito. Apenas uma notícia nas páginas de $O$ Início informa a mensalidade a ser paga pelos alunos do Curso Comercial, sem mencionar a dos demais cursos - primário e médio:

Os alunos matriculados no Curso Comercial apenas com o pagamento de $20 \$ 000$ mensais têm o direito a receber lições de português, inglês, francês, aritmética, álgebra, contabilidade, escrituração mercantil, inclusive noções sobre Direito Comercial, etc.

20- O Início, ano 1, n. 1, 12 out. 1922.

21 - O Início, de tiragem irregular e com mudanças sensíveis em seu formato e proposta, vai ser publicado até 0 ano de 1958, quando é extinto (no então Ginásio e Escola Técnica Saldanha Marinho). A data de seu desaparecimento parece coincidir com a saída do Prof. Penteado do cargo de diretor. 
Aos alunos da Escola Nova são oferecidos passes escolares para os Bondes da Light. ${ }^{22}$

No início dos anos 1910, o governo do Estado de São Paulo, visando fortalecer a organização de um mercado de trabalho constituído por trabalhadores nacionais, criou as primeiras escolas profissionais oficiais para qualificar mão de obra para o setor industrial ${ }^{23}$. 0 preparo de trabalhadores aptos aos serviços e ao comércio ficou, no Estado de São Paulo, entregue à iniciativa particular. Possivelmente, João Penteado associou sua opção pelo ensino de trabalhadores à escolha de uma modalidade requisitada de formação profissional.

De fato, estudo sobre as demandas do mercado de trabalho no setor terciário entre 1920 e 1930, tomando por base 2.025 anúncios publicados no jornal $O$ Estado de São Paulo, afirma que a datilografia era o principal requisito (47\%) do setor, seguido pela exigência de domínio em língua estrangeira (28\%) (CARVALHO, 2005). Entre 1872 e 1920, a população da cidade de São Paulo cresceu dezoito vezes. Segundo o recenseamento de 1920, a distribuição das ocupações na população da Capital era a seguinte: $25,6 \%$ da população da Capital com idade superior a 14 anos estava empregada na indústria; $8 \%$, no comércio e em bancos; 4\%, no serviço doméstico; 3,7\%, em agricultura, criação, caça e pesca, e extração de matérias minerais; 3,6\%, em profissões liberais; 3,5\%, em transportes, correio, telégrafos e telefones. Da população total da Capital (579.033 habitantes), 32\% eram menores de 14 anos; 25\% não tinham profissão; 6\% apresentavam profıssão mal defınida; 0,7\% viviam de rendas; logo, restavam 36\% da população com profissão definida. Conforme Maria Alice Ribeiro (2002), chama a atenção o número de pessoas sem profissão - 146.866 -, 25\% da população da Capital, ou melhor, 37,5\% da população com

22 - O Início, n. 4, 16 out. 1923.

23 - Na mesma época, 1910, foi criada pelo governo federal uma escola profissional de aprendizes artífices nas principais capitais do país, incluindo a de São Paulo. A esse respeito, ver Moraes (2003). mais de 14 anos. Nessa rubrica, as mulheres predominavam, correspondendo a 89\%, e parte significativa dessa participação era composta por donas de casa. 0s 11\% restantes eram homens, possivelmente desempregados, inválidos e estudantes.

0 problema dos sem trabalho não se restringiu ao período de dificuldades econômicas, mas tornou-se um problema crônico da metrópole. A vida na sociedade paulistana sofreu uma série de transformações nos anos 1920: consolidação do modo de vida urbano, integração dos setores industriais, diversificação dos serviços pessoais e do comércio, novas correntes de trabalhadores vindas de outros países e de regiões empobrecidas do país; nesse contexto, os primeiros ensaios de uma legislação trabalhista iriam ocorrer. 0 mercado de trabalho passa a ser objeto de intervenção do Estado ${ }^{24}$. 0 ciclo de greves operárias, que se inicia em 1901 e terá seus pontos culminantes nas greves gerais de 1917 e 1919, inicialmente motivadas por questões salariais, combinará rapidamente a reivindicação econômica à reivindicação política e social, com a exigência de um direito fundamental do trabalho ${ }^{25}$ - jornada de trabalho, seguro contra acidentes, aposentadoria, regulamentação do trabalho do menor, da mulher, férias, horas extras etc. (VIANNA, 1978). 0 clima revolucionário no mundo e em São Paulo, o otimismo da entrada de década saudada pelos anarquistas na grande manifestação operária do Primeiro de Maio de 1919, que reuniu dez mil pessoas na Praça da Sé, são substituídos pelo pessimismo do seu encerramento. E, como afırma

24 - Até 1919, o mercado de trabalho encontrava-se sem qualquer tipo de regulamentação. 0 mundo do trabalho era ordenado segundo as necessidades dos empregadores: o trabalhador podia ser dispensado a qualquer momento sem indenização, não tinha descanso semanal remunerado e nem férias; não havia aposentadoria e pensões, nem limites à jornada de trabalho e regulamento do trabalho de mulheres e crianças (RIBEIR0, 2002; VIANNA, 1978).

25 - Singularmente, como observa Vianna (1978, p. 50), a única produção legal tendo por objeto o mundo do trabalho será referente à vida associativa operária - Decreto n 1.637, de 5 de fevereiro de 1907. Com ele, cria-se 0 direito de associação para todos os "profissionais de profissões similares ou conexas, inclusive as profissões liberais". A lei sindical, antecedida pela agitação operária, vinha simplesmente institucionalizar as organizações nascidas da própria prática operária. 
Ribeiro (2002), nos anos 1920, desenvolve-se, na cidade de São Paulo, o drama da modernidade de uma sociedade capitalista na periferia do capitalismo: o aumento da produtividade e da concentração da riqueza convivendo com a crescente população sem trabalho, subempregada, a incapacidade de modernizar as relações de trabalho e a exclusão social.

A Escola Nova procura manter-se nesse contexto de dificuldades. E sobrevive. Seus meios de propaganda: os próprios alunos, suas famílias e o jornal da escola. Mas quem eram os alunos? Os trabalhadores e seus filhos? Quais trabalhadores, de quais ocupações e segmentos? E, mais uma vez, é essa imprensa e sua escrita juvenil que nos diz algo sobre o perfil social do público da escola. 0 jornal preserva sua organização e as seções expõem conteúdos direcionados às mesmas preocupações sociais, políticas e culturais dos anos da Escola Moderna. As atividades escolares e, em particular, as extraclasse e seus objetivos permanecem: passeios ao ar livre, o contato com a natureza e a vida urbana, o relacionamento entre professores e alunos; enfim, as descobertas por meio da observação e da análise continuam a ser reveladas nos exercícios posteriores de descrição e redação. Com mais frequência, e talvez com maior ênfase, surgem referências aos trabalhadores e às suas condições de vida e trabalho, nas mais diferentes profissões e ocupações. São várias as visitas a lugares e circunstâncias que se relacionam a questões sociais: Vila Maria Zélia, Jardim da Luz e estações de trem, trajeto dos bondes, comércio ou oficinas de pais de alunos, fábricas de vidro, de tecidos, oficinas mecânicas, canteiros de construção, entre outros. A descrição do processo de trabalho e de sua utilidade social aparece sempre e está associada a comentários críticos acerca das condições de sua realização.

Os operários vão buscar então com canas de ferro a matéria líquida para com ele fazerem os objetos por meio de formas. 0 trabalho na fábrica de vidro é muito ruim. Os operários que trabalham na fábrica de vidro sofrem muito, principalmente as crianças que vivem muito mal tratadas e queimadas. ${ }^{26}$

Se o trabalho manifesta-se como trabalho estranhado na sociedade na qual vivemos, ele possui também uma dimensão positiva, como possibilidade de criação e realização do homem que o exerce, na perspectiva da superação do alheamento e da exploração:

0 trabalho é o fator principal de tudo que há de belo, grandioso e sublime neste mundo. Sem ele não haveria cousa alguma que não fosse útil porque sem trabalho não seria possivel a aquisição de bem estar e progresso. $^{27}$

Os alunos escrevem sobre os acontecimentos históricos, mas agora eles se restringem aos de nosso país, como a morte de Tiradentes, a descoberta do Brasil e da América. Da mesma maneira, são brasileiras as figuras expressivas da vida cultural e científica citadas: Luiz Pereira Barreto, Carlos Gomes e Oswaldo Cruz, entre outras. São abordados temas diversos relacionados à formação moral - sobre as consequências do vício, os males do alcoolismo, o valor da instrução. A ênfase no estudo do meio mantém-se, incluindo visitas a algumas cidades do interior e até a capitais de outros Estados, com atenção às diferenças entre as situações de vida e trabalho na roça e na cidade, e, nessa última, à presença do bonde elétrico, do trem e da nova máquina - o automóvel. Outras notícias, em pequeno número, indicam que os alunos também valorizavam apresentações teatrais, como as do grupo dramático Flor da Mocidade, do qual fazia parte Arlindo Ramos, aluno do ensino médio da escola ${ }^{28}$.

26- Arthur Moraes (11 anos), O Início, n. 1, 11 out. 1922

27 - Romão Coca (1 ${ }^{\circ}$ ano do Curso Comercial), O Início, n. 3, 28 maio 1923. 28- O Início, n. 4, 6 out. 1923. 


\section{Considerações finais e apontamentos para pesquisa}

Em 1924, a escola assume nova denominação - Academia de Comércio Saldanha Marinho - e, em seu recém-criado Boletim, apresenta-se como estabelecimento de instrução e educação, em regime de internato e externato,

regulamentado pelo Decreto Federal, de 5 de janeiro de 1905, e autorizado pela Diretoria Geral da Instrução Pública, de acordo com a Lei estadual n. 1579, de 19 de dezembro de $1917 .^{29}$

Conforme a Lei Estadual, que estabelecia as condições para o funcionamento das escolas particulares no Estado, os estabelecimentos de ensino profissional e superior,

embora independentes de autorização para o seu funcionamento, deve[ria]m ser registrados na Diretoria da Instrução Pública e cumprir as disposições da Consolidação das Leis do Ensino. ${ }^{30}$

Estudos realizados por Fernando Antonio Peres (s/d) acerca do ensino comercial indicam a crescente centralização e complexidade de sua estrutura institucional. Em 1923, um novo decreto federal ( ${ }^{0} 4.724-\mathrm{A}$, de 23 de agosto de 1923) equipara os diplomas expedidos por outras instituições de ensino comercial no Brasil aos da Academia de Comércio no Rio de Janeiro, além de determinar a utilização, por todas elas, dos programas de ensino determinados em 1905. Esse decreto também implementou o princípio da fiscalização, pelo governo, dos estabelecimentos de ensino comercial, a ser determinado por lei ou ato governamental, medida adotada três anos depois. 0 regulamento para os estabelecimentos de ensino reconhecidos pelo governo federal, aprovado em 1926 (decreto $\mathrm{n}^{\circ}$ 17.329, de 18 de agosto de 1926),

29-Boletim, 1 jan. 1926.

30- Artigo 50, Anuário do Ensino do Estado de São Paulo, 1918. estabeleceu critérios para os exames de admissão e para a validação e o registro dos diplomas expedidos pelas instituições de ensino comercial. Ficou estabelecido que os concluintes do curso geral recebessem o título de contador e os do curso superior, o de graduado em ciências econômico-comerciais. 0 regulamento também apresentava os mecanismos de fiscalização dessa modalidade de ensino. A fiscalização abrangeria toda a organização e o funcionamento dos estabelecimentos de ensino comercial, especialmente quanto à regularidade das aulas, ao cumprimento de programas, à moralidade dos exames e provas parciais, à suficiência do aparelhamento escolar, à aptidão do corpo docente (com as vagas preenchidas por concurso ou por estágio de no mínimo dois anos) e à legalidade dos diplomas conferidos (PERES, s/d).

0 ensino comercial apareceu pela primeira vez no relatório geral do Ministro da Agricultura em 1926. Segundo esse relatório, com o objetivo de melhorar e coordenar o ensino comercial no país, o decreto aprovado naquele mesmo ano aprofundou a fiscalização e o controle do governo sobre os estabelecimentos do ensino comercial criados pela iniciativa particular (PERES, s/d). Nessas circunstâncias, a então Academia de Comércio Saldanha Marinho solicitou ao governo e obteve, no ano de 1928, a inspeção federal necessária ao seu reconhecimento oficial e ao reconhecimento dos diplomas expedidos. Dois anos depois, é criado o Ministério da Educação e Saúde (decreto n ${ }^{\circ}$ 19.402, de 14 de novembro de 1930), que incorporou a Superintendência dos Estabelecimentos de Ensino Comercial. Em 1931, Francisco Campos promoveu a reforma geral do ensino comercial com a publicação do decreto $n^{\circ}$ 20.158, em 30 de junho de 1931. Composto por 82 artigos, o decreto define a estrutura do ensino comercial reconhecido pelo governo federal: $1^{\circ}$ ciclo: curso propedêutico (três anos); curso de auxiliar de comércio (dois anos); $2^{\circ}$ ciclo: cursos técnicos de secretário (um ano), administrador-vendedor, atuário e perito-contador (três anos). A matrícula nos cursos exigia a 
idade mínima de 12 anos, atestado de saúde e vacinação, assim como pagamento da matrícula e aprovação no exame de admissão. Definia, também, regime escolar, férias, frequência, avaliação, submissão dos programas e escolha dos compêndios à Superintendência, instalações adequadas, provimento de professor por concurso, seriação e organização de bancas para exames finais. A partir de então, a administração do ensino comercial passava a ser exercida não só pelo Conselho Consultivo do Ensino Comercial (uma espécie de Conselho Nacional da Educação para o ramo comercial), órgão destinado a dar pareceres sobre assuntos relativos ao ensino comercial e presidido pelo Ministro da Educação e Saúde Pública, mas também por uma Superintendência do Ensino Comercial, órgão administrativo com funções de direção geral do ensino, fiscalização das escolas e registro de professores (ROMANELLI, 1978). Inúmeras críticas a essa reforma apontam a fiscalização e o controle excessivos que centralizavam as decisões, determinando os programas, tornando rígida e inelástica a organização do ensino (ROMANELLI, 1978). Mostram, sobretudo, o aprofundamento da dualidade estrutural do ensino, a conformação de um ramo profissional fechado, sem comunicação com os outros ramos do ensino médio, terminal em ambos os ciclos, com uma única possibilidade de acesso à educação superior via curso superior de finanças.

Esse quadro de mudanças - de ampliação institucional, crescimento e centralização da atuação dos governos federal e estadual, e de regulamentação da profissão de contador traz novas questões para a análise das práticas escolares. É preciso verificar como elas se realizaram após a intervenção estatal e comparar com os períodos anteriores. As leis podem ser entendidas não apenas como imposições, mas também como artefato propiciador de algumas formas de apropriação, e, nessa perspectiva, cabe às pesquisas apreender se e como as determinações legais instauraram tipos de ordenação social em obediência à lei, ou suscitaram (novas) práticas de resistência. Um contato inicial com os jornais da fase em que a escola ficou conhecida como Academia de Comércio Saldanha Marinho, publicados entre dezembro de 1928 e setembro de 1943 sob a responsabilidade do Grêmio Acadêmico "Saldanha Marinho", indica a preservação dos objetivos presentes nos períodos passados. 0 fato de tanto os alunos dos cursos regulares como os dos cursos profissionais continuarem a participar da elaboração dos jornais, por exemplo, sugere a tentativa de fazer prevalecer o princípio da educação integral, de acordo com o qual a escola permanece ligada ao universo do trabalho a partir de uma proposta que não se limita ao aprendizado do ofício.

Nas comemorações de 1937, acerca do $25^{\circ}$ aniversário da escola, no jornal $O$ Início, o editorial intitulado 13 de Maio (1912-1937) - 25 anos da Academia de Comércio Saldanha Marinho e 49 anos da Abolição da Escravidão traz histórico que descreve o percurso do estabelecimento como dividido em três fases distintas, mas "que se correlacionam perfeitamente, sem ter sofrido solução de continuidade" ${ }^{31}$. A primeira fase, apresentada como a de sua fundação, em 1912, "para acolher os filhos de operários do bairro que não tinham acesso à escola”, e cujo principal objetivo era a alfabetização, vai até 1923, destacando-se, nesse momento, a criação do curso de datilografia e o crescente desenvolvimento da escola. A segunda fase é a da "Escola Nova de Comércio", a qual, com a generalização do título de Academia assumido pelas escolas de comércio, passa a identificar-se também como Academia de Comércio Saldanha Marinho. 0 nome Saldanha Marinho é justificado tanto pela localização da escola na rua de mesmo nome, como pelo fato de o homenageado ter sido "homem bom e de valores morais, simpatizante do abolicionismo e que se preocupava com a causa social", de desempenho destacado no Império (e na Maçonaria Republicana, acrescenta-se). Com o crescente desenvolvimento da escola, inicia-se a terceira fase de sua existência,

31 - O Início, ano XI, n. 52, maio 1937. 
cheia de entusiasmo e vida, assumindo proporções consideráveis: o corpo docente foi melhorado, as matérias foram mais desenvolvidas e o programa foi grandemente ampliado, de modo a tornar-se mais eficiente. ${ }^{32}$

Há muito o que pesquisar e analisar, na direção proposta, a respeito da escola e de suas vivências. 0 contato com as fontes e a literatura acerca do tema indica a necessidade de responder a algumas questões consideradas prioritárias: até quando, quanto ou como resistiram na promoção dos princípios humanitários do anarquismo em suas práticas pedagógicas? Quais distinções podem ser estabelecidas entre o plano de ensino das escolas e as propostas da educação oficial e das correntes educacionais liberais predominantes no período que incidiram sobre as políticas governamentais, como é o caso, sobretudo, do chamado movimento da Escola Nova?

De qualquer maneira, o interesse central desse esforço educacional está em sua apreensão mais complexa e rica de educação.
A educação integral, como sugere Mikhail Bakunin (2003), não se reduz a procedimentos didáticos restritos ao âmbito escolar, mas pressupõe uma visão distinta de sociedade e do trabalho, a construção de uma sociedade igualitária, autogerida. Ao vivenciar tais concepções, os anarquistas lançaram as pontes para o futuro: sua política pedagógica está presente nas lutas atuais pelas formas de igualdade real entre os homens e entre os sexos, pela abolição das classes, nos movimentos ecológicos, na defesa do coletivismo e na afirmação da individualidade, na superação da massificação e do individualismo. E, sobretudo, em nossa luta permanente pela universalização do ensino, pela construção da escola unitária, da educação integral/integrada/politécnica para todos. A radicalidade de seu projeto consiste em tornar a escola um espaço indispensável de reflexão e planejamento do social. É esse, a nosso ver, um dos elos mais ricos da memória legada pelos libertários à história do movimento dos trabalhadores. 


\section{Referências}

BAKUNIN, Mikhail Aleksandrovitch. A instrução integral. São Paulo: Imaginário, 2003.

CALSAVARA, Tatiana da S. Práticas da educação libertária no Brasil: a experiência da Escola Moderna de São Paulo. Dissertação (Mestrado em História e Historiografia da Educação) - Faculdade de Educação, Universidade de São Paulo, 2004.

CAPELLETTI, Ángel J. La ideologia anarquista. Disponível em: <pt.scribd.com/doc/3929794/Angel-J-Cappelletti-La-ideologiaanarquista >. Acesso em: 17 set. 2009.

CARVALHO, Paulo Jorge Oliveira. Ensino profissional para o setor terciário em São Paulo: a relação entre mercado de trabalho e ensino profissional pelos anúncios classificados do jornal "O Estado de S.Paulo" (1920-1930). Dissertação (Mestrado) - Pontifícia Universidade Católica, São Paulo, 2005.

CODELLO, Francesco. A boa educação: experiências libertárias e teorias anarquistas na Europa, de Godwin a Neill. v. I: A teoria. São Paulo: Editora Imaginário, 2007.

FERRER Y GUARDIA, Francisco. La escuela moderna. Madrid: Editora Zero, 1970.

GRAVE, Jean. Las aventuras de Nono. Madrid: Libertarias/Prodhufi S.A., 1991.

JOMINI, Regina Célia Mazoni. Uma educação para a solidariedade. Campinas: Pontes/Editora da UNICAMP, 1990.

LIMA, Mariângela A. de; VARGAS, Maria Theresa. Teatro Operário em São Paulo. In: PRADO, Antonio Arnoni (Org.). Libertários no Brasil: memórias, lutas, cultura. São Paulo: Brasiliense, 1986. p. 150-161.

LUIZETTO, Flávio Venâncio. 0 movimento anarquista em São Paulo: a experiência da Escola Moderna nº 1 (1912-1919). Educação e Sociedade, Campinas, ano VIII, n. 24, p. 18-47, ago. 1986.

As utopias anarquistas. São Paulo: Brasiliense, 1987.

MARQUES, Antonio José. Escola Moderna em São Caetano. Mimeog., s/d, 17 p. (versão revisada. Publicada originalmente como: Escola Libertária em São Caetano. Raízes, São Caetano do Sul, n. 7. jul. 1992).

MORAES, Carmen S. V. A socialização da força de trabalho: instrução popular e qualificação profissional no estado de São Paulo (1873-1934). Bragança Paulista: EDUSF, 2003. (Estudos CDAPH, Série historiografia)

MORAES, Carmen S. V. et al. Inventário de fontes das escolas dirigidas pelo educador anarquista João Penteado (1912-1961): dimensão pedagógica e contribuição para a história da relação trabalho e educação no Brasil. Revista Brasileira de História da Educação, v. 11, n. 1 (25), p. 117-141, jan.-abr. 2011.

MORIYÓN, Felix Garcia (Org.). Educação libertária: Bakunin, Kropotkin, Mella, Robin, Faure. Porto Alegre: Artes Médicas, 1989.

PERES, Fernando Antonio. Alguns apontamentos sobre o ensino comercial no Brasil. mimeogr., s/d, 25 p.

RIBEIRO, Maria Alice Rosa. 0 mercado de trabalho na cidade de São Paulo nos anos vinte. In: SILVA, Sérgio; SZMRECSÁNYI, Tamas (Orgs.). História econômica da Primeira República. São Paulo: Edusp/Hucitec, Imprensa Oficial, 2002. p. 341-368.

RODRIGUES, Edgar. 0 anarquismo na escola, no teatro, na poesia. Rio de Janeiro: Achiamé, 1992.

ROMANELLI, Otaíza. História da educação no Brasil (1930-1973). Petrópolis: Editora Vozes, 1978.

SANTOS, Luciana Eliza dos. A trajetória anarquista do educador João Penteado: leituras sobre educação, cultura e sociedade. Dissertação (Mestrado em Historia e Historiografia da Educação) - Faculdade de Educação, Universidade de São Paulo, 2009. 
SOLÀ, Pere. A escuela y la educación en los médios anarquistas de Cataluña, 1909-1939. In: FERRER Y GUARDIA, Francisco. La escuela moderna. Barcelona: Tusquets Editor, 1978. p. 15-46.

TOMASSI, Tina. Breviario del pensamento educativo libertário. Madrid: Ediciones Madre Tierra; Colômbia: Asociacion Artística "La Cuchilla", 1988.

TRAGTENBERG, Maurício. Francisco Ferrer e a pedagogia libertária. Educação e Sociedade, Campinas, ano Il, n. 1, p. 17-49, set. 1978.

VIANNA, Luiz Wernek. Liberalismo e sindicato no Brasil. Rio de Janeiro: Paz e Terra, 1978.

\section{Fontes/Jornais}

A Lanterna, 1909-1916.

A Vida, 1914-1915.

A Voz do Trabalhador, 1914.

0 Amigo do Povo, 1904.

0 Início, 1915-1919; 1922-1923; 1924-1943.

Boletim da Escola Moderna, 1918-1919.

Carmen Sylvia Vidigal Moraes é professora associada e coordenadora do Centro de Memória da Educação da Faculdade de Educação da Universidade de São Paulo (CME/FEUSP).

Tatiana Calsavara é doutora pela Faculdade de Educação da Universidade de São Paulo, com pesquisa financiada pela Fapesp, e pesquisadora do Centro de Memória da Educação da mesma Faculdade (CME/FEUSP). E-mail: tcalsavara@gmail.com.

Ana Paula Martins é mestre pela Faculdade de Educação da Universidade de São Paulo. E-mail: anap_historia@yahoo.com.br. 